\begin{tabular}{|l|l|}
\hline & \\
&
\end{tabular}

SEÇÃo

\title{
Capitalismo dependente, Estado e autoritarismo no Brasil
}

\author{
Dependent Capitalism, State and Authoritarianism in Brazil
}

\author{
Camila Potyara Pereira ${ }^{1}$ \\ orcid.org/0000-0003-1117-2468 \\ camilapotyara@gmail.com
}

\section{Janaína Lopes do Nascimento Duarte ${ }^{1}$ orcid.org/0000-0003-4847-4048 jana.lopesduarte@gmail.com}

\section{Liliam dos Reis Souza \\ Santos $^{1}$}

orcid.org/0000-0001-6410-6371

Liliamsouza@unb.br

Recebido em: 26 set. 2020 Aprovado em: 4 fev. 2021. Publicado em: 06 maio. 2021.
Resumo: Como resultado de pesquisas sobre a articulação, no Brasil atual, entre Estado, capitalismo dependente e nova direita, este texto enfatiza questões estruturantes e conjunturais das peculiaridades do capitalismo no País, com o objetivo de discutir as relações entre Estado, classes sociais, autocracia burguesa, democracia restrita, nova direita e autoritarismo. Seguindo a perspectiva materialista histórica dialética e referenciado em revisão de literatura especializada, o texto estrutura-se e apresenta como resultados: o entendimento do Estado capitalista como relação social contraditória moldada pelas lutas de classe, suas particularidades no Brasil sob as bases do capitalismo dependente; a heteronomia, padrão compósito de hegemonia burguesa e os limites da democracia no Brasil, como eixos estruturantes e dinâmicos da especificidade brasileira: e o autoritarismo como produto da corrente ideológica da nova direita, com tendência de radicalização, presente nas ações políticas nacionais que seguem caracteristicas do Ur-fascismo.

Palavras-chave: Estado. Capitalismo Dependente. Autoritarismo. Nova direita. Classes sociais.

Abstract: As a result of research on the articulation, in the current Brazil, between State, dependent capitalism and new right, this text emphasizes structural and conjunctural questions of the peculiarities of capitalism in the Country, with the objective of discussing the relations between State, social classes, bourgeois autocracy, restricted democracy, New Right and authoritarianism. Following the dialectical historical materialist perspective and referenced in a specialized literature review, the text is structured and presents as results: the understanding of the capitalist state as a contradictory social relationship shaped by class struggles, its particularities in Brazil under the bases of dependent capitalism; heteronomy, a composite pattern of bourgeois hegemony and the limits of democracy in Brazil, as structural and dynamic axes of Brazilian specificity; and authoritarianism as a product of the ideological current of the New Right, with a tendency to radicalization, present in national political actions that follow characteristics of Ur-fascism.

Keywords: State. Dependent capitalism. Authoritarianism. New right. Social classes.

\section{Introdução}

Na contemporaneidade, urge pensar o Brasil de forma crítica e dialética, vinculando questões antigas e novas para a compreensão do presente em sua complexidade e possibilidades históricas. Com este intento, e a partir de pesquisas realizadas no Grupo de Estudos Político-Sociais (POLITIZA/UnB) sobre a articulação, no Brasil atual, entre Estado, capitalismo dependente e ascensão da nova direita, extremada, as autoras deste texto dialogam sobre questões estruturantes e conjunturais das peculiaridades do capitalismo no País. 
A partir da perspectiva materialista histórica dialética e referenciado nas categorias analiticas totalidade, contradição e mediação, e na revisão de literatura especializada, este artigo tem como objetivo discutir as relações entre Estado, classes sociais, autocracia burguesa, democracia restrita, nova direita e autoritarismo, por considerá-las as "chaves" teórico-metodológicas estratégicas para a análise pretendida. Inicialmente, problematizamos, nos termos de Poulantzas, o Estado capitalista como relação social contraditória, particularizando a análise do Estado brasileiro moldado pelo capitalismo dependente e suas implicações no desenho de um princípio democrático burguês limitado.

No item seguinte, com base na teorização de Florestan Fernandes sobre o capitalismo dependente, empreendemos um debate crítico sobre heteronomia/autonomia, desenvolvimento capitalista, padrão compósito de hegemonia burguesa e limites da democracia no Brasil, como eixos estruturantes e dinâmicos da especificidade brasileira. Na sequência, e como item final, refletimos sobre o autoritarismo como produto da corrente ideológica da nova direita, que possui, inerentemente, tendência de se extremar. Isso, por sua vez, requereu uma breve análise das ações políticas nacionais que, seguindo a definição de Umberto Eco, segue características do Ur-fascismo.

\section{Estado capitalista e suas contradições no Brasil}

O Estado em tela não é uma categoria univoca. Desse modo, assevera-se a sua compreensão como relação social contraditória e orgânica ao modo de produção capitalista, em contraposição à acepção de Estado autônomo e neutro defendido pelas ciências social e política burguesas, que se pautam por uma visão dissociada entre as esferas política e econômica.

Como relação social contraditória, o Estado se revela uma complexa teia de funções e inter-relações que compõem a totalidade do modo de produção capitalista. Assim, não se apresenta como coisa enrijecida, mas como relação que se molda a partir dos embates e lutas de classe e das necessidades expansivas de acumulação do capital que, por sua vez, se alteram a partir das crises inerentes a esse sistema.

Não obstante, mostrar-se, no nivel da aparência, como um elemento unificador de demandas sociais conflitantes no campo da reprodução social, o Estado se configura, essencialmente, como ente dominador. Essa sua indole decorre das contradições do histórico conflito entre classes sociais. Por ser atravessado por essas contradições, o Estado mostra-se, também, elementarmente contraditório, já que, no âmbito das lutas de classe, oferece respostas às reivindicações das classes dominadas, o que impede sua categorização como uma entidade classista exclusivista, ainda que tenha caráter de classe (PEREIRA-PEREIRA, 2009; POULANTZAS, 1980; JESSOP, 2007).

Tais condicionantes, por seu turno, correspondem às particularidades das formações sociais concretas de cada Estado-nação. No Brasil, os fatos histórico-sociais que estão na base de formação do Estado e de seus padrões formais-legais desenharam um perfil de Estado burguês de conotação diversa da que se observa nos paises capitalistas centrais. Tais fatos e padrões não são "um episódio histórico", mas "um fenômeno histórico-estrutural", ocorrido em condições sociais, políticas e econômicas particulares (FERNANDES, 1975a, p. 21).

Dentre essas condições particulares, ressalta-se o modelo de capitalismo vigente na América Latina e, consequentemente, no Brasil, que inaugurou uma realidade dependente. Esta não se configura como uma etapa conjuntural do desenvolvimento capitalista, mas é parte dele, o que exigiu um forte protagonismo do Estado na condução da produção e reprodução capitalista neste território, que acentuou a sua dominação e capacidade de condensação de forças entre classes e frações de classe (FERNANDES, 1975a; OSORIO, 2014).

Associado a essa condição, destaca-se o perfil particular da democracia brasileira, que foge ao estilo democrático burguês instaurado pelas revoluções clássicas nos países capitalistas centrais. As explicações dessa incongruência encontram-se nas heranças econômicas, sociais, culturais e politicas, de traço autocrático, deixa- 
das pelo passado colonial e imperial, ausente de instrumentos que viabilizassem a participação popular nas decisões coletivas. Ao se pautar pelo princípio autocrático, a expansão burguesa no Brasil contou com um modelo político de poder ilimitado, porém restrito aos grupos dominantes, o que conformou "uma democracia de senhores, das elites para as elites, dos mais ricos e poderosos, em suma, uma democracia restrita" (FERNANDES, 1994, p. 100).

Esse desequilibrio fez com que o Estado se inclinasse, de maneira acintosa, para o atendimento das necessidades de lucro do capital. Em decorrência, não se construiu um projeto de soberania e integração nacional em busca de um desenvolvimento econômico menos desigual e menos predatório para a maioria da população. A ausência de avanços democráticos reais impossibilitou a ampliação da dimensão relacional do Estado e, consequentemente, de ganhos sociais mais abrangentes. Pelo contrário, as mediações com as classes sociais se deram por meio de um padrão de dominação que usou de variadas estratégias para sufocar as lutas da classe trabalhadora e da grande massa social despossuida, elementos imbuídos do engodo ideológico do Estado neutro expresso na ideia de Estado como pai dos pobres.

Desse modo, na trajetória política brasileira, à medida em que as lutas sociais caminhavam para engendrar "as condições de existência da civilização" (FERNANDES, 1994, p. 103), situadas em parâmetros democráticos burgueses, movimentos de contra insurgência e antidemocráticos emergiam, evidenciando um padrão social e econômico perverso que só sobrevive sufocando reformas progressistas, até mesmo as inscritas na ordem do capital. Esse é um dos sentidos dos recorrentes regimes de exceção neste país, visto que a ditadura civil militar, de 1964, configurou-se como uma contrarrevolução que procurou impedir "a transição de uma democracia restrita para uma democracia de participação ampliada" (FERNANDES, 1994, p. 105).

A superação da etapa ditatorial capitalista brasileira emergiu tanto como demanda econômica
- decorrente da crise financeira que enfraqueceu esse regime e das novas exigências políticas do capital imperialista financeiro - quanto como demanda social que, por meio de lutas e mobilizações, contribuiu para o recuo da ditadura e para que o Estado brasileiro fosse reconhecido, na Constituição Federal de 1988, como um Estado Democrático de Direito.

A partir desta nova qualificação, tornou-se possivel formalizar as lutas sociais de classe no interior do Estado, o que the assegurou uma dimensão relacional contraditória e condensadora de forças, ampliando, assim, a própria dimensão pública do Estado. Isso representou avanço importante em uma sociedade historicamente segregada em termos políticos e cívicos. Porém, este avanço se deu em um contexto macropolítico no qual a democracia burguesa era, cada vez mais, associada ao mercado e a acumulação capitalista não mais carecia de uma direção política autoritária.

Nessa conjuntura, os poderes econômicos do capitalismo dependente já tinham se cristalizado e autonomizado, não sendo necessárias medidas políticas de cunho impositivo. Com efeito, o Brasil adentrou em uma nova era de dominação marcada pela inclusão política e pela exclusão econômica, ou seja, por um processo dual, caracterizado por uma relativa inclusão democrática das massas às decisões políticas, mas marcada pela desigualdade social e pela pobreza, ambas extremadas.

O acirramento da austeridade econômica vem produzindo um modelo de democratização da pobreza atrelado à democratização da política. As contradições desse processo fazem com que a democracia burguesa assuma um viés ainda mais restrito. Nesse sentido, embora pareça inclusiva, ela, na verdade, constitui mera formalidade; inclui muito pouco e sustenta uma falsa socialização politica que serve para manipular a sociedade e legitimar ações políticas usurpadoras e classistas. Isso porque, "a força do voto serviu apenas para definir a substituição das elites ou da classe reinante que administra o aparato estatal" e não "para definir a agenda nem o rumo dos assuntos públicos [...] ou o espaço de decisões possiveis na chamada democratização" (OSORIO, 2014, p. 244). 
Como tais processos são contraditórios, os espaços democráticos dialéticos se tornaram ambiente de questionamentos e de disputas entre projetos políticos relativamente conflitantes. Esses embates dificultaram a operação da hegemonia da classe dominante sem estratégias de incorporação das classes subalternas. Dessa forma, a ampliação democrática "só poderia se dar na forma de uma democracia de cooptação" (IASI, 2017, p. 311).

Tais contradições e disputas explicam a chegada ao governo do Partido dos Trabalhadores (PT) que, em nome da governabilidade, promoveu ações conciliatórias e ampliou as esferas democráticas e as disputas entre divergentes interesses de classe. Nessa tarefa, "organizou o consenso em torno de alternativa que garantia os patamares de acumulação de capitais e o apassivamento dos trabalhadores nos limites da ordem burguesa" (IASI, 2017, p. 311). De tal modo, "o PT não foi protagonista de uma alternativa socialista para o Brasil, foi protagonista indispensável para a consolidação de uma democracia de cooptação e, com ela, a consolidação da ordem burguesa no nosso país" (IASI, 2017, p. 312).

Nesse cenário, embora tenha feito um governo extremante favorável e inclinado às necessidades acumulativas dos grupos dominantes, já que, segundo dados do jornal valor econômico, no decorrer do governo do ex-presidente Luiz Inácio Lula da Silva, os bancos tiveram lucro 8 (oito) vezes mais do que no mandato de seu antecessor, Fernando Henrique Cardoso (BANCOS..., [2014]), a extensão democrática feriu os interesses do capital financeiro e das elites locais e internacionais, o que, somado aos efeitos da crise econômica em curso, promoveu o exaurimento das medidas de conciliação e ampliou a intolerância às investidas democráticas do Brasil, culminando no golpe parlamentar de 2016. Esse golpe favoreceu "o desaparecimento de limites efetivos ao exercício do poder, em nome da lógica do mercado" (CASARA, 2017, p. 348-353).

Nesse contexto, emergiu com força a autocracia burguesa de talhe autoritário, ainda que dissimu- lada no discurso democrático. Uma das consequências perversas dessa tendência é a ascensão de uma onda ultraliberal/ultraconservadora, que flerta com o fascismo e que tem defendido a construção de um Estado punitivo e repressivo em sua atuação junto às liberdades individuais, de pensamento, de cátedra e organização dos movimentos sociais, enquanto, por outro lado, apoia pautas de liberdade irrestrita ao mercado, resguardando os interesses comerciais do controle popular.

Tem-se, assim, na atualidade brasileira, uma conjuntura política que confirma a tese de Florestan Fernandes (1975a) de que, no Brasil, não predomina uma democracia fraca, mas uma autocracia forte e dissimulada que se acentua à medida em que se amplia a disputa pelo fundo público e pelos espaços do Estado.

\section{Heteronomia, classes sociais, autocracia burguesa, democracia restrita - a especificidade da dependência capitalista no Brasil}

Ao longo da sua vasta obra, Florestan Fernandes construiu uma problematização sobre a formação da sociedade brasileira que carrega grande relevância teórica e política, particularmente para os dias atuais: a concepção de capitalismo dependente como uma das formas que o desenvolvimento capitalista assume no decorrer de sua fase monopólica. As preocupações de Fernandes se pautavam na especificidade brasileira, já que, para ele, as "sociedades formadas no Brasil e na América Latina não constituiam mera reprodução das sociedades europeias" (CARDOSO, 2005, p. 23), apresentando características próprias e singulares.

Fernandes (1972) afirma que um dos elementos estruturantes desse processo seria determinado pela condição colonial permanente do Brasil em relação aos países capitalistas hegemônicos, condição essa que se altera continuamente, perpetuando-se, pois "se redefine no curso da história, mas de tal modo que a posição heteronômica ${ }^{3}$ da economia do País, em sua estrutura e funcio- 
namento, mantém-se constante" (FERNANDES, 1972, p. 14 - nota 2, grifo nosso). A depender da dinâmica externa, o que pode variar "é a natureza do nexo de dependência, a polarização da hegemonia e o poder de determinação do núcleo dominante" (FERNANDES, 1972, p. 14 - nota 2).

Tal característica potencializa as condições da relação entre desenvolvimento e subdesenvolvimento no capitalismo dependente, pois essas são determinadas pelos interesses e vínculos existentes nas conexões dialéticas da organização econômica, social, política e cultural entre as sociedades. Como afirma Fernandes (1995a, p. 139), "não há como coincidir os tempos da história", já que as sociedades consideradas dependentes ou avançadas necessariamente apresentam tempos distintos: as estruturas dos países capitalistas hegemônicos "absorvem as estruturas dos países de capitalismo dependente, submetendo-as a seus próprios ritmos e subordinando-as aos interesses que lhes são próprios" (FERNANDES, 1995a, p. 139), conectando-se à expropriação e exploração acentuada do trabalho, à manutenção de privilégios de uma minoria burguesa e à ampliação da desigualdade. ${ }^{4}$

Logo, necessariamente se estabelece uma relação dialética e contraditória entre os países e/ou regiões capitalistas, na qual os países dependentes assumem uma função determinada e integrada à lógica do capital, pois o "capitalismo dependente gera, ao mesmo tempo, o subdesenvolvimento econômico, social, cultural e político. Ele une o arcaico ao moderno e suscita seja a arcaização do moderno, seja a modernização do arcaico" (FERNANDES, 1975b, p. 61), a partir da "persistência de estruturas socioeconômicas herdadas do passado com a formação de estruturas socioeconômicas novas" (FERNANDES, 1975b, p.
62), exigindo a fusão do moderno com o antigo na produção, no mercado e na organização das classes nas sociedades dependentes.

Destarte, o fundamento para o subdesenvolvimento está contido na explicação sobre o desenvolvimento, no qual a dinâmica das classes sociais assume papel estratégico, já que "como as classes se organizam e cooperam ou lutam entre si" (FERNANDES, 1972, p. 15) constitui-se, também, como elemento estruturante da categoria capitalismo dependente.

Para tratar de classes, a partir de Fernandes (1975b), é necessário frisar que processos combinados de dominação externa e dominação interna se constituem como faces da mesma moeda que acarretam dilemas para as sociedades dependentes na América Latina, a saber: a) estruturas econômicas, socioculturais, politicas que podem até absorver as transformações capitalistas, porém inibindo a integração nacional e o desenvolvimento autônomo; e b) dominação externa que estimula a modernização e o crescimento, mas impedindo a revolução nacional e uma autonomia de fato (FERNANDES, 1975b).

Florestan analisa que as burguesias locais se constituem como parceiras ${ }^{5}$ (ainda que menores e subordinadas) das burguesias hegemônicas, revelando a articulação orgânica entre dominação imperialista (externa) e dominação das burguesias

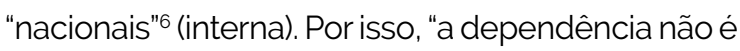
mera condição ou acidente. A articulação estrutural de dinamismos econômicos externos e internos requer uma permanente vantagem estratégica do polo econômico hegemônico, aceita como compensadora, útil e criadora pelo polo dependente" (FERNANDES, 1975b, p. 54, grifo nosso).

Por conseguinte, no capitalismo dependente a dominação externa só se realiza por meio da

\footnotetext{
4 A lógica do capitalismo dependente é caracterizada por um padrão dual de expropriação do excedente econômico (alimentando a manutenção simultânea, interna e externa, de poder econômico, político, cultural nacional e internacional), o que "[...] envolve, estrutural e dinamicamente, tanto uma extrema concentração interna da renda, quanto uma dominação externa e uma drenagem de recursos permanentes" (FERNANDES, 1975b, p. 28)

5 Fernandes (1995b, p. 134) ressalta que "a burguesia tende [...] a criar um espaço político seguro [...] essa burguesia só é débil para promover a revolução burguesa segundo o modelo 'clássico', nacionalista democrático. Ela é bastante forte para preservar o seu poder real, usar o Estado nacional para se proteger e, especialmente, para estabelecer políticas econômicas que assegurem continuidade e aceleração do crescimento econômico sem maiores repercussões no grau de democratização e de nacionalização das estruturas de poder". 6 A partir das obras de Fernandes, compreendemos que as chamadas burguesias locais não se definem ou se organizam a partir de marcos nacionais unificados e genéricos, mas se definem, sobretudo, em função de interesses determinados pela sua própria natureza de classe (burguesa), em sintonia com a lógica do capital, cujos vinculos são profundos e diferenciados em relação às burguesias internacionais. Por isso, utilizamos o termo "burguesia nacional" entre aspas e preferimos o temo "burguesias locais".
} 
dominação interna, conduzida por forças sociais internas, sendo, por isso, as burguesias locais não passivas neste processo. Para Fernandes (1975b, p. 67), o processo de formação da sociedade de classes no Brasil, como especificidade dependente capitalista, "não elimina distinções e barreiras sociais aberrantes (desde o periodo colonial), consolida-as ou as renova sob novas aparências", exacerbando desigualdades de maneira naturalizada, em que uma minoria retém privilégios como se fossem direitos, excluindo a maioria da sociedade de todos os seus direitos.

Em suas análises sobre as peculiaridades da sociedade de classes sob o capitalismo dependente, Fernandes (1975b) destaca a exacerbação do elemento político e suas consequências, a partir da conexão entre três aspectos:

a) incompatibilidade entre privilegiamento de classe e democracia, na qual a tentativa de conciliação, nos países dependentes, gera tendências autocráticas ou autoritárias por parte da burguesia, a depender dos seus interesses, circunstâncias e poder de luta dos trabalhadores. O superprivilegiamento de classe constitui-se como "fator de diferenciação social e de estabilidade nas relações de poder entre as classes" (FERNANDES, 1975b, p. 104), sendo impossibilitada sua conciliação com a "adoção de sistemas políticos constitucionais e representativos" (FERNANDES, 1975b, p. 104). O resultado é a conversão em uma democracia restrita, limitada à burguesia, a partir de uma aparência democrática que, de fato, "deforma a democracia com participação ampliada" (FERNANDES, 1975b, p. 105).? Para preservar o superprivilegiamento de classe no capitalismo dependente é necessário um Estado burguês típico/ específico, em constante reformulação das relações autocráticas e autoritárias; a depender das "ameaças" da classe trabalhadora à burguesia, pode-se passar da conciliação para o endure- cimento: "em suas modalidades mais brandas e estáveis, esse Estado é autocrático e autoritário; nas modalidades mais duras e extremas, esse Estado é totalitário e dissimuladamente fascista" (FERNANDES, 1975b, p. 106, grifo nosso);

b) constituição de um padrão compósito de hegemonia burguesa, já que "ao aburguesamento da oligarquia corresponde um processo mais amplo e complexo de aburguesamento das outras camadas sociais" (FERNANDES, 1975b, p. 107). Isso ocorre segundo um processo de adaptação em que: articulam-se parceiros estrangeiros; há o ajustamento/aburguesamento generalizado entre aristocracia, camadas médias e pequeno burguesas; somado ao privilegiamento da alta burguesia, complexificando as relações e estruturas de poder. Conforme Fernandes (1975b, p. 108, grifo nosso), a melhor palavra de que se dispõe para designar essa "conglomeração de posições, interesses, grupos e subgrupos, formas de solidariedade de classes e orientação básica no uso do poder político não é oligarquia, mas plutocracia. Esse padrão de hegemonia burguesa é um produto do caráter dependente e subdesenvolvido da economia capitalista". Este padrão exige uma racionalidade capitalista intensamente conservadora, já que objetiva "proteger a ordem, a propriedade individual, a iniciativa privada, a livre empresa e a associação dependente, como fins instrumentais para a perpetuação do superprivilegiamento" (FERNANDES, 1975b, p. 108), partindo sempre dos mesmos fins, ainda que os meios possam variar, segundo o contexto histórico e as particularidades de cada país dependente;

c) Negação das demais classes, abalando as condições de existência como classes dentro da própria ordem e impondo, à maioria explorada, a persistência e o agravamento da desigualdade

O debate sobre a sociedade de classes e sua relação com a democracia restrita no capitalismo dependente culmina, segundo Fernandes (1995a, p. 142), na análise da Revolução Burguesa no Brasil: "[...] sua evolução em quadros particulares, não levam à revolução burguesa clássica, nem ao Estado representativo democrático burguês ou à autonomia nacional. É preciso romper com o modelo clássico (de Revolução Burguesa) para compreender o capitalismo da periferia e aonde ele conduz". 
e da ausência de direitos, bem como o acirramento das condições de subordinação e organização dos trabalhadores, reproduzindo o pacto da dependência.

A articulação desses três aspectos, que conduzem à renovação de conflitos e dilemas sociais locais e que não serão resolvidos na esfera do capitalismo dependente, tenderão a se redefinir em novos niveis, mais complexos, assumindo formas mais graves a depender da dinamicidade das relações de classe em determinado momento histórico.

No Brasil, vive-se tempos dificeis e complexos na dinâmica atual do capitalismo dependente em que categorias teóricas, aqui recuperadas a partir das obras de Florestan Fernandes, como heteronomia, binômio desenvolvimento/ subdesenvolvimento, classes sociais, autocracia burguesa e democracia restrita possibilitam desnudar, criticamente, aspectos estruturantes e dinâmicos das relações capitalistas em solo brasileiro. As contradições e relações (novas e antigas) entre as classes fundamentais e suas frações tendem a se renovar, mantendo aspectos estruturantes de desigualdade e dominação burguesa interna e externa.

"A configuração estrutural da sociedade de classes dependente e subdesenvolvida subordina a estabilidade e a transformação da ordem existente à expansão do capitalismo em condições de heteronomia permanente" (FERNANDES, 1975b, p. 72, grifo nosso), sem condições de sustentar um desenvolvimento que seja de fato autônomo e que estimule a democracia ampliada e a garantia de direitos para a classe trabalhadora. São tempos de negação de direitos, de retrocessos democráticos (intensificando a lógica da democracia restrita), de opressão e de avanços ultraliberais e ultraconservadores, por meio de um Estado cada vez mais comprometido com os privilégios da autocracia burguesa, inclusive com o uso de modalidades mais duras e extremas, autoritárias.

\section{Nova direita e autoritarismo}

Como visto, a formação sócio-histórica brasileira, com particularidades expressas no complexo colonial, racista, patriarcal, classista e dependente, culminou no perfil estatal burguês contemporâneo, que mantém as cascas da democracia, mas, em essência, revela conteúdo autoritário, sempre a serviço das elites nacionais e supranacionais.

Essa autocracia burguesa, patrimonialista e tirânica, serviu de base para a propagação, em escala mundial, de duas ideologias de direita que, amalgamadas, possuem alto potencial de radicalização: o neoliberalismo e o neoconservadorismo. ${ }^{8}$ Fundidas sob o signo da nova direita, sintetizam a defesa coexistente de um Estado mínimo na proteção social e na regulação do mercado, por um lado, e de um Estado forte no resgate da ordem e dos valores tradicionais, por outro.

A nova direita, germinada na década de 1960 nos Estados Unidos, só se tornou hegemônica a partir do final dos anos 1970, com a posse de governos alinhados com os postulados ideológicos dessa corrente, como o de Ronald Reagan, nos EUA; Margareth Thatcher, na Grã-Bretanha; Augusto Pinochet, no Chile; Helmut Khol na Alemanha, para citar os mais notórios. No entanto, antes de caracterizar regimes politicos ou governantes, os valores neodireitistas já proliferavam nas instituições mercantis e empresariais, nas igrejas, nas escolas, nas familias.

No Brasil, embora a nova direita só tenha chegado ao poder após o golpe de 2016, encontrou adeptos, na sociedade civil, desde a sua constituição. O crescimento da legitimidade popular aos seus pressupostos foi progressivo e constante: impulsionado nos anos de chumbo da Ditadura civil militar, ocorrida entre 1964 e 1985; ampliado pelos governos neoliberais de Fernando Collor de Mello (1990-1992), Itamar Franco (1992-1995) e Fernando Henrique Cardoso (1995-2003); perseguido, pelas classes médias frustradas, como estratégia de enfrentamento aos avanços sociais promovidos pelos governos petistas de Luís Inácio Lula da Silva e Dilma Rousseff (2003-2016); e escancarado com

8 Para maiores informações sobre cada ideologia em particular e sobre a Nova Direita como corrente ideológica ver King (1987), George e Wilding (1994), Brown (2006, 2015) e Pereira (2016, 2019) 
o golpe de 2016 e com a eleição de Jair Bolsonaro à Presidência da República em 2018.

Essa corrente ideológica, que acredita na desigualdade social como pré-requisito imprescindivel para o progresso, advoga em favor da restrição das medidas de proteção social à classe trabalhadora e da negação dos direitos humanos e sociais (KING, 1987). Ainda assim, a despeito de subsidiar o conjunto de princípios que movem a burguesia, encontra defensores também entre aqueles que são, por ela, mais prejudicados.

Percebe-se que sua disseminação abrangente só pode se dar em um contexto histórico, político e social de uso incessante da manipulação da opinião pública e da mentira. É mediante o artifício obsessivo das fake news; do ataque aos intelectuais e às universidades; do descrédito de cientistas; do repúdio ao pensamento crítico e aos fatos; da reconstrução da história, por meio de uma narrativa mítica; e da eleição eterna de inimigos - reais ou não -, que o terreno para a fixação desta ideologia como corrente dominante e universal se torna fértil.

A nova direita carrega, em seu seio, uma radicalização latente. O neoliberalismo e o neoconservadorismo que a constituem já não podem ser analisados isoladamente. Amalgamados, não são mais duas correntes, essencialmente contrárias, embora tenham historicamente compartilhado convicções centrais, que se uniram em prol da satisfação de seus interesses comuns. Representam a união imanente do que há de mais perverso em cada uma em separado. Assim, na defesa do livre mercado, vem embutida a ode ao laissez-faire, à meritocracia e à necropolítica. $\mathrm{Na}$ tentativa de resgate dos "bons costumes" e dos valores tradicionais, emergem, no bojo, o racismo, a misoginia, a LGBTfobia. No orgulho patriota, aflora a xenofobia e a islamofobia. Da devoção a Deus, deriva a perseguição a outras expressões religiosas, especialmente as de matriz africana. Em suma, a convergência medular que transforma duas correntes em uma, é a que se direciona para negação - nunca assumida - da democracia.

A nova direita no poder, extremada, edifica um Estado punitivo, penal, refém do mercado, das grandes corporações mundiais, autoritário e substancialmente antissocial. Nuno Ramos (2020), por exemplo, afirma que o governo Bolsonaro possui um projeto de poder claro, mas que, ao contrário de outros governos de direita, não mira no aumento dos lucros do capital ou na solidificação de valores conservadores tradicionais. A ideia de poder dos líderes que estão à frente deste governo parece ser, única e exclusivamente, "a de agredir alguém, um inimigo verdadeiro ou imaginário - ou o primeiro que passar. [...] Alguém precisa urgentemente sofrer, perder, apanhar. Ser caluniado. Morto" (RAMOS, 2020, p. 36). Essa potência agressiva que, para o autor, é isolada, disfuncional, narcisista e inclusiva apenas na sua capacidade de molestar tudo e todos em tempo integral, carrega algo de pré ou pós-político, já que detesta o contraditório, o coletivo, o diverso. O poder, neste contexto, se consolida na violência e no ódio, que deixam de ser meio, para se tornarem o fim.

Entendendo fascismo como uma "sinédoque, uma denominação pars pro toto para os mais diversos movimentos totalitários" (ECO, 2018, p. 32), já que sua versão original, italiana, "não era uma ideologia monolítica, mas antes uma colagem de diversas ideias políticas e filosóficas, um alveário de contradições" (ECO, 2018, p. 32), pode-se afirmar, sem medo de incorrer em imprecisões teóricas e conceituais, que a metodologia governista brasileira atual inspira-se neste tipo de autoritarismo capitalista, mas de caráter eterno, Ur-fascista.

Eco enumera catorze características que o qualificam: o culto à tradição; a recusa da modernidade, com a consequente identificação com o irracionalismo; o culto à ação pela ação, sem reflexão, conforme ilustra a suposta afirmativa de Goebbels: "quando ouço falar em cultura, pego logo a pistola" (ECO, 2018, p. 49); a rejeição ao pensamento crítico, já que "o desacordo é traição" (ECO, 2018, p. 49); o racismo e o medo do diferente; o apelo às classes médias frustradas, como auditório alienado e rancoroso; o nacionalismo como privilégio e a xenofobia como autoproteção contra complôs externos; a inveja e o medo dos 
inimigos "ao mesmo tempo fortes demais e fracos demais" (ECO, 2018, p. 52); a crença em uma guerra permanente e o antipacifismo; o elitismo e o elogio à hierarquia com forte desprezo pelos considerados "fracos"; o heroísmo e o culto da morte, sendo que a espera pela própria morte heroica "provoca, com maior frequência, a morte dos outros" (ECO, 2018, p. 54); o machismo, com profunda repulsa pelas mulheres e LGBT e uma permanente "inveja do pênis"; o populismo qualitativo, com oposição ferrenha aos "podres poderes parlamentares". Conforme ECO (2018, p. 58), "cada vez que um político põe em dúvida a legitimidade do Parlamento por não representar mais a 'voz do povo', pode-se sentir o cheiro do Ur-fascismo". E, por fim, a novilingua orwelliana, composta por um "léxico pobre e uma sintaxe elementar, com o fim de limitar os instrumentos para o raciocínio complexo e crítico" (ECO, 2018, p. 59). Ou, conforme Murgia (2019, p. 33), "uma comunicação eficaz e mais banal possivel. Banal". Todas podem ser observadas, em maior ou menor grau, nas ações do presidente Jair Bolsonaro e de seus asseclas.

Conforme já sinalizado neste texto, a presença forte de um Estado, com essas caracteristicas, endurece ou afrouxa a depender das ameaças que enxerga na classe trabalhadora. Igualmente, pode se fazer mais ou menos autoritário a partir das demandas populacionais. O espanhol Ignácio Ramonet (2020) reflete que, quanto maior e mais traumático o medo coletivo, maior é o desejo por Estado, autoridade, orientação. O risco é que essa alta demanda por Estado converta-se na aceitação pacífica do autoritarismo estatal, ou do estatismo autoritário, no dizer de Poulantzas (1980), da ditadura, da repressão e da violência. Hoje, assiste-se, com consternação, o clamor de parcela da população por intervenções militares variadas. Diante da pandemia do COVID-19, que assola o globo desde dezembro de 2019, várias são as nações que derrubaram o direito à privacidade e impuseram a vigilância absoluta de seus cidadãos por meio de seus aparelhos de celular. Não tem sido incomum, também, o apelo por pautas autoritárias de prisão ou tortura a quem descumprir o isolamento social e sair de casa, seja qual for a motivação. De acordo com a pesquisa do Instituto da Democracia e da Democratização da Comunicação (INCT), realizada em 2018, $47,8 \%$ da população brasileira é favorável a um golpe militar diante de muita corrupção e 53,2\%, quando há muito crime. Mais Estado, assim, não é, necessariamente, mais proteção social, mais bem-estar, mais direitos.

\section{Considerações finais}

A articulação das categorias Estado, classes sociais, autocracia burguesa, nova direita e autoritarismo, foi a temática desenvolvida neste texto. Para tanto, abordou-se os principais elementos que caracterizam a formação sociopolítica do Estado brasileiro, a exemplo do capitalismo dependente que privilegiou o principio autocrático em detrimento do democrático, constituindo um Estado de forte indole dominadora, que sufoca as lutas da classe trabalhadora e, consequentemente, limita sua dimensão relacional e respostas sociais progressivas às classes dominadas no campo das relações sociais capitalistas, aguçando sua natureza de classe burguesa.

Ainda com base nas determinações sociais do capitalismo dependente, a partir de Florestan Fernandes, refletiu-se sobre a constituição das classes sociais no Brasil, demarcando o papel estratégico e estruturante da classe dominante para o capitalismo dependente, haja vista, que as burguesias locais, ainda que em uma condição subalterna, mostram-se parceiras da dominação externa das burguesias imperialistas, já que promovem e reproduzem estratégias de dominação interna e, assim, mantém status e privilégios a pequenos grupos, excluindo a classe dominada dos avanços no campo dos direitos, cidadania e da democracia burguesa. Tais elementos, estruturantes das relações sociais burguesas brasileiras, explicam a dinâmica e conjuntura atual deste país, marcada pela negação de direitos da classe trabalhadora, dominação, opressão e autoritarismo.

Sob este solo, tem se propagado duas ideologias mundiais da direita, o neoliberalismo e neoconservadorismo que se confluem na nova direita, cujas pautas de um Estado mínimo, pro- 
teção social pelo mercado e valores tradicionais casam-se com as estruturas politicas e sociais conservadoras brasileiras, reatualizando processos de manipulação e cooptação das massas por meio da reprodução de fake news, do desprezo à ciência e repúdio ao pensamento diverso e crítico.

Essas facetas são parte de uma radicalização latente do ódio de classe que compõem a natureza da meritocracia, da necropolítica, racismo, misoginia e LGBTfobia. Estes elementos agrupam vários segmentos conservadores da sociedade brasileira, como as igrejas evangélicas neopentecostais, os defensores do livre mercado e grupos extremistas que flertam com fascismo e nazismo. Essas frações sociais, consideradas algumas diferenças, convergem na negação da democracia em prol da autocracia, do autoritarismo e do UR-fascismo. Tragicamente, esses processos autocráticos e autoritários se reatualizam em um contexto de crise sanitária, esfacelando ainda mais as duras mediações sociais presentes neste país, exacerbando o caráter predatório do capitalismo dependente que nos marca.

\section{Referências}

BANCOS lucraram 8 vezes mais no governo de Lula do que no de FHC. 2014. Valor Econômico, 12 set. 2014. Disponivel em: https://veja.abril.com.br/economia/ bancos-lucraram-8-vezes-mais-no-governo-de-lula-do-que-no-de-fhc. Acesso em: 7 fev. 2021

BROWN, Wendy. Undoing the Demos: Neoliberalism's Stealth Revolution. New York: Zone Books, 2015

BROWN, Wendy. American Nightmare: Neoliberalism, Neoconservatism, and Democratization. In: Political Theory, v. 34, n. 6, p. 690-714, Dec. 2006.

CARDOSO, Miriam Limoeiro. Sobre a teorização do capitalismo dependente em Florestan Fernandes. In: FÁVERO, Osmar (org.). Democracia e educação em Florestan Fernandes. Campinas, SP: Autores Associados; Niterói, RJ: EDUFF, 2005. p. 7-40.

CASARA, Rubens R. R. O estado pós-democrático [recurso eletrônico]: neo-obscurantismo e gestão dos indesejáveis/ Rubens R. R. Casara. Edição do Kindle. 1. ed. Rio de Janeiro: Civilização Brasileira, 2017. Recurso digital

ECO, Umberto. O Fascismo Eterno. Rio de Janeiro; São Paulo: Editora Record, 2018

FERNANDES, Florestan. Capitalismo Dependente e Imperialismo. In: Em busca do socialismo: últimos escritos e outros textos. São Paulo: Xamã, 1995a. p. 139-144
FERNANDES, Florestan. Imperialismo e Revolução Autocrático-Burguesa. In: Em busca do socialismo: últimos escritos e outros textos. São Paulo: Xamã, 1995b. p. 133-138.

FERNANDES, Florestan. Democracia e Desenvolvimento: A transformação da periferia e o Capitalismo Monopolista da Era Atual. São Paulo: Hucitec, 1994.

FERNANDES, Florestan. A revolução burguesa no Brasil: ensaio de interpretação sociológica. Rio de janeiro: Zahar, 1975a.

FERNANDES, Florestan. Capitalismo dependente e classes sociais na América Latina. 2. ed. Rio de Janeiro: Zahar, 1975b.

FERNANDES, Florestan. Sociedade de classes e subdesenvolvimento. In: Sociedade de classes e subdesenvolvimento. Biblioteca de Ciências Sociais. Rio de Janeiro: Zahar, 1972. p. 9-90

GEORGE, Vic; WILDING, Paul. Welfare and Ideology. New York: Harvester/Wheatsheaf, 1994.

IASI, Mauro. Política, Estado e Ideologia na trama conjuntural. São Paulo: Expressão Popular - ICP, 2017.

INCT. A cara da Democracia no Brasil. Satisfação com a democracia e a conjuntura política no Brasil. Relatório N. 1 de divulgação de pesquisa nacional realizada pelo Instituto Nacional de Ciência e Tecnologia (INCT) - Instituto da Democracia e da Democratização da Comunicação. Belo Horizonte-Brasília-Campinas-Rio de Janeiro: INCT, maio/2018.

JESSOP, Bob. O Estado e a Construção de Estados. Outubro - Revista do Instituto de Estudos Socialistas, São Paulo, n. 15, p. 1516-6333, 2007.

KING, Desmond. The New Right: Politics, Markets and Citizenship. London: The Macmillan Press, 1987.

MURGIA, Michela. Instruções para se tornar um fascista. Biblioteca Antagonista. Belo Horizonte: Editora Âyiné, 2019

OSORIO, Jaime. O Estado no Centro da Mundialização - A sociedade civil e o tema do poder. 1. ed. Tradução de Fernando Correa Prado. São Paulo: Outras expressões, 2014.

PEREIRA, Camila Potyara. Proteção Social no Capitalismo: crítica a teorias e ideologias conflitantes. São Paulo: Cortez, 2016.

PEREIRA, Camila Potyara. Nova direita e Política Social: neoliberalismo, neoconservadorismo e a negação de direitos. In: GÓlS, João Bôsco Hora; SOUZA, Sidimara Cristina. Temas de Politica Social: análises e discussões. Curitiba: Editora CRV, 2019. v. 1.

PEREIRA-PEREIRA, Potyara Amazoneida Pereira. Estado, sociedade e esfera pública. In: CFESS; ABEPSS. (org.). Serviço Social: Direitos Sociais e Competências Profissionais. 1. ed. Brasilia: CFESS, 2009. v. 1, p. 285-300.

POULANTZAS, Nicos. O Estado, o poder, o socialismo Rio de Janeiro, Edições Graal, 1980. 
RAMONET, Ignacio. Ante lo desconocido...La pandemia y el sistema-mundo. In: Cuba Debate, Especiales, Sociedad, 25 abr. 2020. Disponivel em: http://www.cubadebate. cu /especiales/2020/04/25/especial-de-ignacio-ramonet-ante-lo-desconocido-la-pandemia-y-el-sistema-mundo/\#.XvZycChKjIX. Acesso em: 3 maio 2020.

RAMOS, Nuno. O Baile da Ilha Fiscal. Folha de S.Paulo, São Paulo, 3 de maio de 2020. Ilustríssima - Coronavirus. Disponivel em: https://Www1.folha.uol.com.br/ ilustrissima /2020/05/brasil-enfrenta-duplo-apocalipse-com-bolsonaro-e-coronavirus-reflete-nuno-ramos.s html. Acesso em: 4 maio 2020.

\section{Camila Potyara Pereira}

Doutora em Política Social pela Universidade de Brasilia (UnB), em Brasilia, DF, Brasil, professora do Departamento de Serviço Social e do Programa de Pós-Graduação em Política Social (PPGPS) da UnB. Vice coordenadora do Núcleo de Estudos e Pesquisas em Política Social (NEPPOS/UnB) e líder do Grupo de Estudos Político-Sociais (POLITIZA/PPGPS/UnB), inscrito no Diretório dos Grupos de Pesquisa do CNPq.

\section{Janaína Lopes do Nascimento Duarte}

Doutora em Serviço Social pela Universidade Federal do Rio de Janeiro (UFRJ), no Rio de Janeiro, RJ, Brasil; professora do Departamento de Serviço Social e do Programa de Pós-Graduação em Política Social (PPGPS) da UnB. Pesquisadora do Núcleo de Estudos e Pesquisas em Politica Social (NEPPOS/UnB) e do Grupo de Estudos Politico-Sociais (POLITIZA/PPGPS/UnB), bem como vice-coordenadora da Rede Capitalismo Dependente, Educação e Serviço Social (CADESS), ambos inscritos no Diretório dos Grupos de Pesquisa do CNPq.

\section{Liliam dos Reis Souza Santos}

Doutora em Política Social pela Universidade de Brasília (UnB), em Brasilia, DF, Brasil; professora do Departamento de Serviço Social da mesma instituição. Coordenadora do Núcleo de Estudos e Pesquisas em Política Social (NEPPOS/UnB) e vice-lider do Grupo de Estudos Político-Sociais (POLITIZA/PPGPS/UnB), inscrito no Diretório dos Grupos de Pesquisa do CNPq.

\section{Endereço para correspondência}

Camila Potyara Pereira; Janaina Lopes do Nascimento Duarte:

Liliam dos Reis Souza Santos

Universidade de Brasilia

Campus Universitário Darcy Ribeiro

Departamento de Serviço Social

Instituto Central de Ciências (ICC)

Asa Norte, 70910-900

Brasilia, DF, Brasil 